\title{
25 Research Soure \\ The Effects of Melatonin Treatment on Oxidative Stress Induced by Ovariohysterectomy in Dogs
}

\section{Sina Salavati}

Shiraz University School of Veterinary Medicine

Asghar Mogheiseh ( $\nabla$ mogheiseh@yahoo.com )

Department of Clinical Sciences, School of Veterinary Medicine, Shiraz University

https://orcid.org/0000-0002-3136-2288

\section{Saeed Nazifi}

Shiraz University School of Veterinary Medicine

\section{Atefeh Amiri}

Shiraz University School of Veterinary Medicine

\section{Behrooz Nikahval}

Shiraz University School of Veterinary Medicine

\section{Research article}

Keywords: Dog, Surgery, Oxidative stress, Melatonin, Antioxidants

Posted Date: December 10th, 2020

DOI: https://doi.org/10.21203/rs.3.rs-123019/v1

License: (c) (i) This work is licensed under a Creative Commons Attribution 4.0 International License.

Read Full License 


\section{Abstract}

Background: As one of the most common surgeries performed in veterinary medicine, ovariohysterectomy $(\mathrm{OHE})$ can induce stress in dogs. The antioxidant properties of melatonin have been confirmed in various studies. This study aimed to investigate the effects of melatonin administration on oxidative stress in dogs before and after OHE. In this study, 25 mature female intact dogs were selected and randomly divided into five equal groups: Melatonin, $\mathrm{OHE}$, melatonin+OHE+melatonin, melatonin+anesthesia+melatonin, and control groups. Melatonin $(0.3 \mathrm{mg} / \mathrm{Kg} / \mathrm{day}$, p.o.) was administrated to the dogs in the melatonin, melatonin+OHE+melatonin, and melatonin+anesthesia+melatonin groups on days $-1,1,2$, and 3 (day $0=\mathrm{OHE}$ ). Blood sampling was performed on days $-1,1,3$, and 5 of the study. Blood samples were immediately transferred to the laboratory and sera were separated and stored at $-20^{\circ} \mathrm{C}$. Superoxide dismutase (SOD), glutathione peroxidase (GPX), and catalase (CAT) concentrations were significantly higher in the melatonin and melatonin+anesthesia+melatonin groups compared to those of the control group.

Results: The level of antioxidant enzymes significantly decreased in the OHE group compared to that of other groups. The administration of melatonin increased the level of antioxidant enzymes in ovariohysterectomized dogs. OHE significantly increased the concentration of malondialdehyde (MDA) in comparison to that of other groups. Melatonin administration significantly decreased the level of MDA in intact, anesthetized, and ovariohysterectomized dogs.

Conclusions: It can be stated that the administration of melatonin one day before and during one week after OHE could control oxidative stress in dogs with increased antioxidant enzymes and decreased MDA levels.

\section{Background}

Increased reactive oxygen species (ROS) can cause damage to macromolecules (lipids and proteins), lead to cell damage, and decrease ROS scavenging mechanisms, resulting in oxidative stress [1,2]. There are several markers that can be used to investigate the changes in the oxidative status. These markers are substances that are formed as a result of the reaction between ROS and biomolecules. One of these substances produced through the above reaction is malondialdehyde (MDA), which is a useful indicator of lipid peroxidation [2-4]. Another oxidative stress indicator is catalase (CAT), which catalyzes hydrogen peroxide detoxification $[2,5]$. Glutathione is a non-enzymatic antioxidant that is involved in vitamin metabolism and plays a key role in cell membrane protection $[3,6]$. As antioxidant enzymes, Glutathione peroxidase (GPX) and superoxide dismutase (SOD) activate the enzymatic defense system against ROS $[3,7]$.

In recent years, many studies have been designed to measure oxidative stress markers after spaying and propose some solutions to reduce oxidative stress [8]. As an elective and sometimes urgent method of spaying, ovariohysterectomy (OHE) has been reported to have some early side effects, such as increased 
oxidative stress due to traumatic events during surgery, ischemia, increased levels of free iron and copper released from tissues, and inflammation of serous membranes $[2,3,9])$. The balance between oxidants and antioxidants is crucial for living organisms to remain healthy and functional [10]. It has been shown that oxidative stress during the postmenopausal period can lead to some metabolic disorders, such as osteoporosis and cardiovascular diseases [11-13]. In addition, some studies have reported that ovariectomy could have long-term effects, including increased oxidative stress and a decrease in estrogen and ovarian hormones, on rats [1].

As a neurotransmitter, melatonin (N-acetyl-5-methoxytryptophan) is a hormone produced and released by the pineal gland or epiphysis during the night in a circadian rhythm [14]. Under special conditions, the neuroendocrine cells of other organs, including the thyroid gland, retina, skin, and gastrointestinal tract, can also produce melatonin in vertebrates [15]. In our previous experiments, we found that melatonin could have anti-oxidative, anti-inflammatory, and anti-stress effects and regulate the secretion of metabolic hormones in dogs following castration [16-19].

Due to the antioxidant effects of melatonin and the presence of oxidative stress in dogs undergoing open ovariectomy [9], the present study aimed to evaluate the effects of melatonin treatment on oxidative stress before and after OHE and anesthesia.

\section{Results}

The mean concentrations and activities of antioxidant enzymes (SOD, GPX, and CAT) and the oxidative stress index (MDA) were compared between the study groups (Fig. 2). Furthermore, the effects of time (days of sampling) and group (melatonin, $\mathrm{OHE}$, melatonin $+\mathrm{OHE}+$ melatonin, melatonin + anesthesia + melatonin, and control) were analyzed for each factor in this study (Table 1). 
Table 1

The changes in mean \pm SEM antioxidant enzymes, including superoxide dismutase (SOD), glutathione peroxidase (GPX), and catalase (CAT), and oxidative stress index (malondialdehyde (MDA)) were compared between different groups and different sampling days in each group. Melatonin was administrated on days $-1,1,3$, and 5 and OHE surgery was performed on day 0 .

\begin{tabular}{|c|c|c|c|c|c|}
\hline Factors & Groups & Day - 1 & Day 1 & Day 3 & Day 5 \\
\hline \multirow[t]{5}{*}{$\begin{array}{l}\text { SOD } \\
(\mathrm{U} / \mathrm{gHb})\end{array}$} & Melatonin $(n=5)$ & $\begin{array}{l}\mathrm{a} 1063.8 \pm \\
7.31\end{array}$ & $\begin{array}{l}{ }^{b} 1080.2 \pm \\
6.39^{a}\end{array}$ & ${ }^{b c} 1087 \pm 5.89^{a}$ & $\begin{array}{l}\mathrm{c} 1093.4 \pm \\
6.42^{\mathrm{a}}\end{array}$ \\
\hline & $\mathrm{OHE}(\mathrm{n}=5)$ & $\begin{array}{l}\mathrm{a} 1064.6 \pm \\
7.35\end{array}$ & ${ }^{b} 1045 \pm 6.36^{c}$ & ${ }^{b} 1037 \pm 7.40^{b}$ & $\begin{array}{l}{ }^{b} 1041.6 \pm \\
6.91^{b}\end{array}$ \\
\hline & $\begin{array}{l}\mathrm{Mel}+\mathrm{OHE}+\mathrm{Mel}(\mathrm{n}= \\
\text { 5) }\end{array}$ & $\begin{array}{l}\mathrm{a} 1066.2 \pm \\
7.50\end{array}$ & $\begin{array}{l}\mathrm{b} 1052.6 \pm \\
6.31^{c}\end{array}$ & $\begin{array}{l}\mathrm{b} 1045.4 \pm \\
7.74^{\mathrm{b}}\end{array}$ & $\begin{array}{l}{ }^{b} 1048.8 \pm \\
6.90^{b}\end{array}$ \\
\hline & $\begin{array}{l}\text { Mel + Anesthesia + } \\
\text { Mel }(n=5)\end{array}$ & ${ }^{\mathrm{a}} 1064 \pm 7.23$ & $\begin{array}{l}\mathrm{ac} 1075.2 \pm \\
6.24^{\mathrm{ab}}\end{array}$ & $\begin{array}{l}\mathrm{bc} 1081.8 \pm \\
6.30^{\mathrm{a}}\end{array}$ & ${ }^{b} 1091 \pm 6.98^{a}$ \\
\hline & Control $(n=5)$ & $\begin{array}{l}1063.4 \pm \\
6.65\end{array}$ & $\begin{array}{l}1065.4 \pm \\
6.65^{b}\end{array}$ & $\begin{array}{l}1061.4 \pm \\
6.65^{c}\end{array}$ & $\begin{array}{l}1062.6 \pm \\
8.60^{c}\end{array}$ \\
\hline \multirow[t]{5}{*}{$\begin{array}{l}\text { GPX } \\
(\mathrm{U} / \mathrm{gHb})\end{array}$} & Melatonin $(n=5)$ & $\begin{array}{l}480.4 \pm \\
7.43\end{array}$ & $486.2 \pm 7.51$ & $492.2 \pm 7.57^{a}$ & $\begin{array}{l}496.2 \pm \\
7.63^{\mathrm{a}}\end{array}$ \\
\hline & $\mathrm{OHE}(\mathrm{n}=5)$ & $\begin{array}{l}479.2 \pm \\
7.28\end{array}$ & $470.6 \pm 7.01$ & $465.8 \pm 7.03^{b}$ & $\begin{array}{l}468.2 \pm \\
6.83^{b}\end{array}$ \\
\hline & $\begin{array}{l}\text { Mel + OHE + Mel }(n= \\
5)\end{array}$ & $\begin{array}{l}478.2 \pm \\
7.85\end{array}$ & $475.4 \pm 7.35$ & $\begin{array}{l}470.8 \pm \\
6.15^{b c}\end{array}$ & $\begin{array}{l}472.8 \pm \\
6.79^{b}\end{array}$ \\
\hline & $\begin{array}{l}\text { Mel + Anesthesia + } \\
\text { Mel }(n=5)\end{array}$ & $\begin{array}{l}479.4 \pm \\
7.43\end{array}$ & $484 \pm 7.64$ & $\begin{array}{l}489.8 \pm \\
7.64^{\text {ac }}\end{array}$ & $\begin{array}{l}493.6 \pm \\
7.50^{\mathrm{a}}\end{array}$ \\
\hline & Control $(n=5)$ & $\begin{array}{l}478.2 \pm \\
7.28\end{array}$ & $479 \pm 6.87$ & $479.6 \pm 7.26$ & $477 \pm 8.02$ \\
\hline \multirow[t]{4}{*}{$\begin{array}{l}\text { CAT } \\
(\mathrm{U} / \mathrm{gHb})\end{array}$} & Melatonin $(n=5)$ & ${ }^{\mathrm{a}} 0.7 \pm 0.01$ & ${ }^{b} 0.74 \pm 0.02^{a}$ & $\begin{array}{l}{ }^{c} 0.782 \pm \\
0.02^{a}\end{array}$ & $\begin{array}{l}{ }^{d} 0.814 \pm \\
0.02^{a}\end{array}$ \\
\hline & $\mathrm{OHE}(\mathrm{n}=5)$ & $\begin{array}{l}\mathrm{a} 0.704 \pm \\
0.02\end{array}$ & $\begin{array}{l}\mathrm{b}_{0.656 \pm} \pm \\
0.01^{\mathrm{b}}\end{array}$ & $\begin{array}{l}{ }^{c} 0.604 \pm \\
0.02^{b}\end{array}$ & $\begin{array}{l}{ }^{\mathrm{b}} 0.672 \pm \\
0.01^{\mathrm{b}}\end{array}$ \\
\hline & $\begin{array}{l}\mathrm{Mel}+\mathrm{OHE}+\mathrm{Mel}(n= \\
5)\end{array}$ & $\begin{array}{l}\mathrm{a} 0.706 \pm \\
0.02\end{array}$ & $\begin{array}{l}\mathrm{b}_{0} 0.676 \pm \\
0.02^{\mathrm{b}}\end{array}$ & ${ }^{c} 0.64 \pm 0.02^{c}$ & $\begin{array}{l}{ }^{a b} 0.684 \pm \\
0.01^{b}\end{array}$ \\
\hline & $\begin{array}{l}\text { Mel + Anesthesia + } \\
\text { Mel }(n=5)\end{array}$ & $\begin{array}{l}\mathrm{a} 0.71 \pm \\
0.02\end{array}$ & $\begin{array}{l}{ }^{\mathrm{a}} 0.734 \pm \\
0.02^{\mathrm{a}}\end{array}$ & $\begin{array}{l}{ }^{\mathrm{b}} 0.772 \pm \\
0.02^{\mathrm{a}}\end{array}$ & $\begin{array}{l}{ }^{c} 0.804 \pm \\
0.02^{a}\end{array}$ \\
\hline
\end{tabular}




\begin{tabular}{|c|c|c|c|c|c|}
\hline Factors & Groups & Day - 1 & Day 1 & Day 3 & Day 5 \\
\hline & Control $(n=5)$ & $\begin{array}{l}{ }^{a b} 0.702 \pm \\
0.01\end{array}$ & $\begin{array}{l}{ }^{a b} 0.712 \pm \\
0.01^{a}\end{array}$ & $\begin{array}{l}{ }^{a} 0.692 \pm \\
0.01^{d}\end{array}$ & ${ }^{b} 0.72 \pm 0.01^{c}$ \\
\hline \multirow[t]{5}{*}{$\begin{array}{l}\mathrm{MDA} \\
(\mathrm{mmol} / \mathrm{L})\end{array}$} & Melatonin $(n=5)$ & $\begin{array}{l}\mathrm{a} 0.55 \pm \\
0.01\end{array}$ & $\begin{array}{l}{ }^{a b} 0.532 \pm \\
0.01^{a}\end{array}$ & ${ }^{c} 0.5 \pm 0.01^{a}$ & $\begin{array}{l}{ }^{\mathrm{b}} 0.504 \pm \\
0.01^{\mathrm{a}}\end{array}$ \\
\hline & $\mathrm{OHE}(\mathrm{n}=5)$ & $\begin{array}{l}{ }^{\mathrm{a}} 0.56 \pm \\
0.008\end{array}$ & $\begin{array}{l}{ }^{b} 0.632 \pm \\
0.00^{8 b}\end{array}$ & $\begin{array}{l}{ }^{b} 0.622 \pm \\
0.01^{b}\end{array}$ & $\begin{array}{l}{ }^{\mathrm{a}} 0.584 \pm \\
0.01^{\mathrm{bc}}\end{array}$ \\
\hline & $\begin{array}{l}\text { Mel + OHE + Mel }(n= \\
5)\end{array}$ & $\begin{array}{l}{ }^{c} 0.548 \pm \\
0.008\end{array}$ & $\begin{array}{l}{ }^{b} 0.602 \pm \\
0.01^{b c}\end{array}$ & $\begin{array}{l}{ }^{a b} 0.586 \pm \\
0.009^{c}\end{array}$ & $\begin{array}{l}{ }^{\mathrm{ac}} 0.564 \pm \\
0.01^{\mathrm{b}}\end{array}$ \\
\hline & $\begin{array}{l}\text { Mel + Anesthesia + } \\
\text { Mel }(n=5)\end{array}$ & $\begin{array}{l}\mathrm{a} 0.554 \pm \\
0.01\end{array}$ & $\begin{array}{l}{ }^{a b} 0.538 \pm \\
0.01^{a}\end{array}$ & ${ }^{b} 0.51 \pm 0.01^{a}$ & $\begin{array}{l}{ }^{b} 0.512 \pm \\
0.01^{a}\end{array}$ \\
\hline & Control $(n=5)$ & $\begin{array}{l}0.564 \pm \\
0.01\end{array}$ & $0.576 \pm 0.01^{c}$ & $0.554 \pm 0.01^{d}$ & $\begin{array}{l}0.572 \pm \\
0.01^{c}\end{array}$ \\
\hline \multicolumn{6}{|c|}{$\begin{array}{l}\text { abcd In each column, different superscript letters on the right side of mean } \pm \text { SEM indicate signifi } \\
\text { differences between groups with regard to each study variable. } \\
\text { abcd In each row, different superscript letters on the left side of mean } \pm \text { SEM indicate significant } \\
\text { differences between sampling days in each group. }\end{array}$} \\
\hline \multicolumn{6}{|c|}{ Note: $\mathrm{Mel}=$ Melatonin; $\mathrm{OHE}=$ Ovariohysterectomy. } \\
\hline
\end{tabular}

\section{SOD level}

The SOD level decreased in the ovariohysterectomized dogs in comparison with that of the dogs in the control, melatonin, and melatonin + anesthesia + melatonin groups $(P<0.0001)$. Melatonin administration increased the SOD level in the intact and melatonin + anesthesia + melatonin groups compared to the $\mathrm{OHE}$ and melatonin $+\mathrm{OHE}+$ melatonin groups $(\mathrm{P}<0.0001)$. There were no significant differences between the melatonin and melatonin + anesthesia + melatonin groups; thus, it can be concluded that anesthesia did not have an effect on the SOD level. No significant differences were observed between the OHE and melatonin $+\mathrm{OHE}+$ melatonin groups, indicating that treatment with melatonin could not compensate for the reduction in the SOD level in the OHE group compared to the control group $(P=0.004$; Fig. 2).

On the day before OHE, there were no significant differences between the study groups in terms of the SOD level. One day after OHE, there were significant differences between all groups, except between the melatonin vs. melatonin + anesthesia + melatonin, OHE vs. melatonin + OHE + melatonin, and control vs. melatonin + anesthesia + melatonin groups. The level of SOD activity decreased in the ovariohysterectomized dogs one day after surgery $(P<0.03)$ but increased in all groups treated with melatonin $(P<0.03)$, except for melatonin + anesthesia + melatonin and melatonin $+\mathrm{OHE}+$ melatonin groups. On days 3 and 5 after $\mathrm{OHE}$, the mean SOD level was significantly different between all groups ( $P$ 
$<0.02)$, except between the OHE vs. melatonin $+\mathrm{OHE}+$ melatonin and melatonin vs. melatonin + anesthesia + melatonin groups (Table 1).

In the control group, there were no significant differences in the SOD level between sampling days. Melatonin administration in intact dogs significantly increased the SOD level between day -1 vs. days 1 , 3 , and 5 of the study $(P<0.002)$ and day 1 vs. day $5(P=0.02)$. A significant decrease in the level of SOD was observed between day -1 vs. days 1,3 , and 5 in the $\mathrm{OHE}$ and melatonin $+\mathrm{OHE}+$ melatonin groups $(P<0.01)$. Also, significant differences were observed in the SOD level between day -1 vs. days 3 and 5 in the melatonin + anesthesia + melatonin group $(P<0.003)($ Table 1$)$.

\section{GPX level}

A significant decrease was observed in the level of GPX in the ovariohysterectomized dogs compared with the dogs in other groups $(\mathrm{P}<0.0004)$, except for the melatonin $+\mathrm{OHE}+$ melatonin group. Melatonin administration significantly increased the level of GPX in intact and anesthetized dogs compared with the dogs in other groups $(P<0.0001)$. The administration of melatonin did not significantly increase the GPX level in the ovariohysterectomized dogs compared with the OHE and control groups (Fig. 2).

On days - 1 and 1 of sampling, there was no significant difference between any of the groups in terms of the GPX level. On day 3, the mean GPX level was significantly different between melatonin vs. OHE and melatonin $+\mathrm{OHE}+$ melatonin groups $(\mathrm{P}<0.03)$ and between $\mathrm{OHE}$ vs. melatonin + anesthesia + melatonin groups $(P=0.01)$. On day 5 , melatonin administration significantly increased the GPX level in intact and anesthetized dogs compared with the dogs in the $\mathrm{OHE}$ and melatonin $+\mathrm{OHE}+$ melatonin groups $(\mathrm{P}<0.04)$ (Table 1).

Interestingly, no significant difference was observed between sampling days for any of the study groups regarding the level of GPX (Table 1).

\section{CAT level}

Melatonin administration significantly increased the CAT level in intact and anesthetized dogs compared to the dogs in the $\mathrm{OHE}$ and melatonin $+\mathrm{OHE}+$ melatonin groups $(\mathrm{P}<0.003)($ Fig. 2$)$.

On day - 1 of sampling, there was no significant difference between the study groups regarding the CAT level. On day 1 , OHE significantly decreased the CAT level in the OHE and melatonin $+\mathrm{OHE}+$ melatonin groups compared to the control and melatonin + anesthesia + melatonin groups $(P<0.03)$. Also, melatonin administration significantly increased the CAT level in the intact dogs compared with dogs in the $\mathrm{OHE}$ and melatonin $+\mathrm{OHE}+$ melatonin groups $(\mathrm{P}<0.0001)$. There were significant differences between all groups $(P<0.01)$ on day 3 of sampling, except between the melatonin vs. melatonin + anesthesia + melatonin groups. On day 5 , while there were no significant differences between melatonin vs. melatonin + anesthesia + melatonin groups and between $\mathrm{OHE}$ vs. melatonin $+\mathrm{OHE}+$ melatonin groups regarding the level of CAT, there was a significant difference between all other groups regarding the level of CAT $(P<0.01)($ Table 1$)$. 
The increase in the level of CAT was significantly different between all days of sampling in the melatonin group $(P<0.01)$. In the OHE group, the decrease in the level of CAT was significantly different between all days of sampling $(P<0.01)$, except between day 1 vs. day 5 . The level of CAT was not significantly different between day 5 vs. days -1 and 1 in the melatonin $+\mathrm{OHE}+$ melatonin group, but it was significantly different between other sampling days $(P<0.03)$. In the melatonin + anesthesia + melatonin group, the administration of melatonin led to significant differences in the level of CAT between sampling days $(P<0.01)$, except between day -1 vs. day 1 . There was no significant difference in the CAT level between sampling days, except between day 3 vs. day 5 , in the control group (Table 1 ).

\section{MDA level}

While OHE led to an increase in the MDA level, the administration of melatonin decreased its level. The MDA level was significantly different between all groups $(P<0.0001)$, except between the melatonin vs. melatonin + anesthesia + melatonin and control vs. melatonin $+\mathrm{OHE}+$ melatonin groups (Fig. 2) .

On day - 1 of sampling, there was no significant difference between the study groups in terms of the MDA level. A significant difference was observed between all groups, except between the melatonin + $\mathrm{OHE}+$ melatonin vs. OHE and control and between the melatonin vs. melatonin + anesthesia + melatonin groups, on day $1(P<0.01)$. On day 3 , there were significant differences between all groups $(P<0.04)$, except between the melatonin vs. melatonin + anesthesia + melatonin groups. On day 5 , the administration of melatonin significantly decreased the MDA level in intact dogs compared with the dogs in other groups $(P<0.0001)$. The MDA levels were not significantly different between the melatonin + $\mathrm{OHE}+$ melatonin vs. OHE and control and between the OHE vs. control groups (Table 1).

In the control groups, there was no significant difference between sampling days. In the melatonin group, the decrease in the level of MDA was significantly different between day $-1 \mathrm{vs}$. days 3 and 5 and between day 1 vs. day $3(P<0.02)$. In the OHE group, the increase in the level of MDA was significantly different between all sampling days $(P<0.006)$, except between day -1 vs. day 5 and day 1 vs. day 3 . In the melatonin $+\mathrm{OHE}+$ melatonin group, a significant difference was observed between day $-1 \mathrm{vs}$. days 1 and 3 and between day 1 vs. day $5(P<0.006)$. In the melatonin + anesthesia + melatonin group, the decrease in the level of MDA was significantly different between day -1 vs. days 3 and $5(P<0.002)$ (Table 1).

\section{Discussion}

As documented in the previous studies and verified in the present study, a decrease in the level of antioxidant enzymes can lead to increased oxidative stress. According to the present results, melatonin treatment could increase the expression of antioxidant enzymes (SOD, GPX, and CAT) and significantly decrease the MDA level in the surgery groups. Although melatonin increased the levels of SOD, GPX, and CAT in all melatonin groups, the oxidative stress induced by surgery seemed to be so high that melatonin could not completely modulate the activity of these antioxidant enzymes. Anesthesia seemed to lead to less oxidative stress because the activities of antioxidant enzymes significantly increased in the 
anesthesia groups that received melatonin. In addition, in the melatonin-treated groups, melatonin led to a decrease in the level of MDA, which had reached its peak after 3 days.

There are also some other surgical procedures, such as OHE in dogs and abdominal hysterectomy in women, that have been reported to increase lipid peroxidation $24 \mathrm{~h}$ after surgery [3, 21]. In Sakundech et al.'s (2020) study, the MDA level reached its peak 3 days after OHE in dogs but the CAT level did not differ significantly between treatment days. They also reported that the pain score reached its maximum after 3 days due to inflammation caused by tissue injury. Similar results were reported by Quarterone et al. (2017), who compared ovariohysterectomized and ovariectomized dogs and rats regarding postoperative analgesia (Quarterone et al., 2017). Sakundech et al. (2020) also concluded that due to the oxidative stress caused by OHE, the ovariohysterectomized dogs should receive some treatment that can protect their bodies from free radicals $[2,22]$.

Furthermore, Serin et al. (2008) observed that OHE and anesthesia, induced by a combination of Ketamine-Xylazine, could lead to an increase in the oxidative stress markers (Glutathione and MDA). The toxicity of drugs commonly used in anesthesia can induce oxidative stress [3]. Gunay (1999) reported a significant decrease in antioxidative capacity in dogs after enflurane anesthesia [23]. In another study, it was observed that the serum level of vitamin $\mathrm{E}$ and beta-carotene significantly decreased whereas the serum level of vitamin A and MDA significantly increased during enflurane anesthesia in dogs [24].

According to Aengwanich et al. (2019), male dogs were not under oxidative stress after castration due to the non-significant changes in the oxidative stress markers, such as MDA and CAT. However, they concluded that antioxidant treatment may be beneficial for the male dogs in their study because they observed a decrease in total antioxidant capacity (TAC) on days 3,7 , and 10 compared to day 14 [25]. OHE under ketamine-xylazine anesthesia was found to increase lipid peroxidation and decreased antioxidant enzyme activity in rats [13]. The activities of SOD, GPX, and CAT decreased in bitches affected with pyometra due to oxidative stress, but their activities increased after OHE [7].

The post-spaying period in dogs is similar to the post-menopausal period in women. Six weeks after surgical menopause, the decrease in the blood estrogen may lead to some changes in oxidant and antioxidant status. It has also been shown that estrogen therapy, alone or in combination with progesterone, in perimenopausal and postmenopausal women can improve the antioxidant status. Moreover, some studies have suggested that estrogen can lead to higher concentrations of essential trace elements, of which some are antioxidants, in the body and that estrogen itself may serve as an antioxidant and thus prevent the oxidation of lipoproteins [26-28]. Based on these studies, those women who underwent surgical menopause showed increased oxidative stress while in those who retained their ovaries, estrogen levels increased after surgery. Accordingly, it can be stated that estrogen is a potential endogenous protector against oxidative stress even in postmenopausal women.

Several studies have reported an increase in the oxidative stress biomarkers after $\mathrm{OHE}[2,23]$. Therefore, the researchers should find a way that minimizes the harmful effects of free radicals. Melatonin has been shown in numerous studies to have antioxidant properties [17, 29]. Mogheiseh et al. (2019) found that 
dogs were under oxidative stress after castration and that melatonin improved the antioxidant status of intact and castrated dogs [17].

Gautier and et al. (2020) investigated the physiologic effects of hyperbaric oxygen (HBO) therapy on healthy dogs after OHE. They found that while this therapy, at the dose used in their study, had no adverse effects on the treated group, it was ineffective in reducing postoperative inflammation and improving the oxidative status in them[30]. In their study on the effects of flunixin meglumine (FM) and meloxicam on postoperative and oxidative stress after OHE, Yilmaz et al. (2014) reported that while FM reduced postoperative stress, it had no influence on the oxidative stress status [31]. Salavati et al. (2018) examined the effects of melatonin treatment on the levels of sexual hormones, serotonin, and cortisol in intact and castrated male dogs. Their results showed that melatonin increased the level of serotonin but decreased the level of cortisol in intact and castrated dogs [16]. Taheri et al. (2019) also studied the effects of melatonin administration on the levels of thyroid hormones, leptin, and ghrelin in intact and castrated male dogs. They observed that melatonin could regulate metabolic hormones and mitigate the metabolic side-effects of castration [18]. Furthermore, melatonin has been shown to regulate the activation or inhibition of several transcription factors related to antioxidant response, which can justify the antioxidative effects of this substance [29].

\section{Conclusion}

In summary, melatonin administration at a dose of $0.3 \mathrm{mg} / \mathrm{kg}$ on days before and after OHE surgery increased the activities of antioxidant enzymes and decreased the level of MDA, a lipid peroxidation index, leading to reduced oxidative stress. Melatonin was also found to improve the antioxidant status of dogs after anesthesia. There are many factors, including the dose of melatonin administered, the time of melatonin administration (before and after surgery), and the type (open versus closed) and duration of surgery, that could influence the results of studies such as the present study. Therefore, more studies are required to investigate the effects of each of these factors and their correlation on the final results.

\section{Methods}

This experiment was performed in accordance with the Iranian animal ethics framework under the supervision of the Iranian Society for the Prevention of Cruelty to Animals and Shiraz University Research Council (IACUC no: 4687/63).

\section{Animals}

Twenty-five clinically healthy mixed-breed adult female dogs, aged about 1-3 years and weighing 15$20 \mathrm{~kg}$, were used in this study. The dogs were owned and kept by Shiraz University School of Veterinary Medicine. All the dogs were ovariohysterectomized at the end of the study and kept in a NGO shelter. All dogs were fed with commercial dog food (300 g/dog/day; Nutripet ${ }^{\mathrm{T}}$; Behintash Co., Karaj, Iran) and given ad libitum access to water. The dogs were kept under a controlled condition with 12:12 $\mathrm{h}$ light/dark 
cycles. During the first two weeks of acclimatization, the animals were treated with antiparasitics (fenbendazole, 150 mg; pyrantel embonate, 144 mg; praziquantel, 50 mg; Caniverm, 0.7 mg/10 kg, p.o.). The overall health of dogs was evaluated daily during the study by checking their body temperature, heart rate, respiratory rate, appetite, and behavior at the time of feeding and cleaning of their shelter. The pregnancy status of dogs was examined by transabdominal ultrasonography.

\section{Experimental design}

As in our previous studies, melatonin was administrated daily just before and after spaying. Also, since the effect of anesthesia on oxidative stress had to be examined in comparison with other groups [16-19], the dogs were divided into five equal groups $(n=5)$ in a case-control randomized study (Fig. 1). The melatonin group received melatonin $(0.3 \mathrm{mg} / \mathrm{kg}$, p.o.) once daily on days $-1,0,1,2$, and 3 . The dogs in the OHE group were spayed on day 0 but did not receive melatonin. The dogs in the Melatonin-OHEMelatonin group were spayed on day 0 and received melatonin on days $-1,0,1,2$, and 3 . The dogs in the melatonin + anesthesia + melatonin group were anesthetized on day 0 and received melatonin on days $1,0,1,2$, and 3 . The control group was neither spayed nor received melatonin during the study. Blood sampling was performed from the jugular vein into simple glass tubes on days $-1,1,3$, and 5 (Fig. 1). The serum was separated from each blood sample by centrifugation at $750 \times \mathrm{g}$ for 10 minutes and stored at $-20^{\circ} \mathrm{C}$ until laboratory assays.

\section{Ovariohysterectomy}

Ten dogs were ovariohysterectomized under general anesthesia on day 0 . The animals were kept off food and water for 12 hours prior to the surgery. The anesthetic protocol used in this study was selected at the discretion of the anesthesiologist assigned to the case. The dogs were premedicated with acepromazine $(0.05 \mathrm{mg} / \mathrm{kg}$, i.m.) and xylazine ( $0.5 \mathrm{mg} / \mathrm{kg}$, i.m.). Anesthesia was induced with ketamine $(5 \mathrm{mg} / \mathrm{kg}$, i.v. $)$ and diazepam $(0.25 \mathrm{mg} / \mathrm{kg}$, i.v.). After endotracheal intubation, general anesthesia was maintained with isoflurane $(1.2 \%)$ vaporized in oxygen using intermittent positive pressure ventilation. Ketoprofen ( $1 \mathrm{mg} / \mathrm{kg}, \mathrm{i} . \mathrm{m}$.) and ampicillin $(20-10 \mathrm{mg} / \mathrm{kg}$, i.m.) were administered at the induction and the end of surgery [20].

\section{Laboratory measurements}

The following commercial kits were used to colorimetrically measure the activity levels of SOD $(\mathrm{U} / \mathrm{gHb})$, GPX (U/gHb), and CAT (U/gHb) (ZellBio Company, Germany; SOD, Cat. No. ZB-SOD-96A; GPX, Cat. No. ZBGPX-96A; CAT, Cat. No. ZB-CAT-96A) at 420, 412, and $540 \mathrm{~nm}$ in hemolyzed RBCs, following the manufacturer's instructions. The assay kit sensitivity was $1 \mathrm{unit} / \mathrm{ml}$ for SOD and 5 units/ml for GPX.

An assay kit purchased from ZellBio GmbH (Germany) was used to measure MDA (mmol/L; Cat. no. ZBMDA-96A). In this kit, MDA is measured based on its reaction with thiobarbituric acid in an acidic condition and high temperature. The color complex was measured colorimetrically at $535 \mathrm{~nm}$.

\section{Statistical analysis}


All data are presented as mean \pm standard error. The statistical analysis of the data was performed by two-way repeated-measures ANOVA and Tukey's test using GraphPad Prism version 6 (GraphPad Software, San Diego, California, USA). The significant level was set at $\mathrm{P}<0.05$.

\section{Abbreviations}

Ovariohysterectomy (OHE); superoxide dismutase (SOD); glutathione peroxidase (GPX); catalase (CAT); malondialdehyde (MDA); reactive oxygen species (ROS); total antioxidant capacity (TAC); hyperbaric oxygen (HBO); flunixin meglumine (FM); enzyme-linked immunosorbent assay (ELISA); analysis of variance (ANOVA);

\section{Declarations}

\section{Ethics approval and consent to participate}

Our study was submitted to and approved by Iranian animal ethics framework under the supervision of the Iranian Society for the Prevention of Cruelty to Animals and Shiraz University Research Council (IACUC no: 4687/63). It is confirmed that the informed consent, written, was obtained from the shelter. The recommendations of European Council Directive (2010/63/EU) of September 22, 2010, regarding the standards in the protection of animals used for experimental purposes, were also followed.

\section{Consent to publish}

Not applicable.

\section{Availability of data and material}

Datasets generated and/or analyzed during the current study are available by the authors in request.

\section{Competing interests}

We would like to confirm that there are no known conflicts of interest associated with this publication.

\section{Funding}

This study was supported financially by School of Veterinary Medicine, Shiraz University (Grant No. 97GCU2M154630). There was no significant financial support for this work that could have influenced its outcome. The funding body had no role in the design of the study and collection, analysis, and interpretation of data and in writing the manuscript.

\section{Authors' contributions}

All authors have seen and approved the final version of the manuscript being submitted. All authors contributed to all parts of the study, from designing the study to writing and preparing the manuscript. $\mathrm{AM}, \mathrm{SS}$ and AA contributed to the study design, implementation of the study, sampling, data collection 
and analysis, and manuscript preparation. SN helped in designing and performing the study and doing the laboratory metabolites analysis. BN contributed to the implementation of the study and ovariohysterectomy.

\section{Acknowledgments}

Not applicable.

\section{References}

1. Szczubial M, Kankofer M, Bochniarz M, Dąbrowski R. Effects of ovariohysterectomy on oxidative stress markers in female dogs. Reprod Domest Anim. 2015;50(3):393-9.

2. Sakundech K, Chompoosan C, Tuchpramuk P, Boonsorn T, Aengwanich W. The influence of duration on pain stress, oxidative stress, and total antioxidant power status in female dogs undergoing ovariohysterectomy. Veterinary World. 2020;13(1):160.

3. Serin G, Kiral F, Serin I. Acute effect of ovariohysterectomy on lipid peroxidation and some antioxidant levels in dogs. Bull Vet Inst Pulawy. 2008;52:251-3.

4. Khoubnasabjafari M, Ansarin K, Jouyban A. Reliability of malondialdehyde as a biomarker of oxidative stress in psychological disorders. Biolmpacts: BI. 2015;5(3):123.

5. Mehaney DA, Darwish HA, Hegazy RA, Nooh MM, Tawdy AM, Gawdat HI, El-Sawalhi MM. Analysis of oxidative stress status, catalase and catechol-0-methyltransferase polymorphisms in Egyptian vitiligo patients. PLoS One. 2014;9(6):e99286.

6. Hayden RE, Paniello RC, Yeung CS, Bello SL, Dawson SM. The effect of glutathione and vitamins A, C, and E on acute skin flap survival. Laryngoscope. 1987;97(10):1176-9.

7. Gogoi J, Leela V, Suganya G, Shafiuzama M, Vairamuthu S, Rajamanickam K, Pandiyan ASS. Effect of ovariohysterectomy on oxidative stress markers in pyometra affected bitches. Int J Chem Stud. 2018;6(4):994-8.

8. Michelsen J, Heller J, Wills F, Noble G. Effect of surgeon experience on postoperative plasma cortisol and C-reactive protein concentrations after ovariohysterectomy in the dog: a randomised trial. Aust Vet J. 2012;90(12):474a-478.

9. Lee JY, Kim MC. Comparison of Oxidative Stress Status in Dogs Undergoing Laparoscopic and Open Ovariectomy. The Journal of Veterinary Medical Science. 2014;76:273-6.

10. Tomsič K, Seliškar A, Lukanc B, Svete AN. Plasma total antioxidant capacity and activities of blood glutathione peroxidase and superoxide dismutase determined in healthy dogs by using commercially available kits. Acta Veterinaria. 2016;66(4):534-48.

11. Kankofer M, Radzki R, Bieńko M, Albera E. Anti-oxidative/oxidative status of rat liver after ovariectomy. Journal of veterinary medicine series A. 2007;54(5):225-9.

12. Castelao JE, Gago-Dominguez M. Risk factors for cardiovascular disease in women: relationship to lipid peroxidation and oxidative stress. Medical hypotheses. 2008;71(1):39-44. 
13. Elvan A. Effect of ovariohysterectomy on some oxidative stress markers in the rat. Harran Üniversitesi Veteriner Fakültesi Dergisi. 2016;5(2):124-8.

14. Haldar C: Experimental endocrinology and reproductive biology: Science Publishers; 2008.

15. Ambriz-Tututi M, Rocha-González HI, Cruz SL, Granados-Soto V. Melatonin: a hormone that modulates pain. Life Sci. 2009;84(15-16):489-98.

16. Salavati S, Mogheiseh A, Nazifi S, Tabrizi AS, Taheri P, Koohi F. Changes in sexual hormones, serotonin, and cortisol concentrations following oral administration of melatonin in castrated and intact dogs. Journal of Veterinary Behavior. 2018;27:27-34.

17. Mogheiseh A, Koohi F, Nazifi S, Tabrizi AS, Taheri P, Salavati S. Oxidative-antioxidative status and hepatic and renal factors following melatonin administration in castrated and intact dogs. Basic Clinical Andrology. 2019;29(1):1-11.

18. Taheri P, Mogheiseh A, Tabrizi AS, Nazifi S, Salavati S, Koohi F. Changes in thyroid hormones, leptin, ghrelin and, galanin following oral melatonin administration in intact and castrated dogs: a preliminary study. BMC Vet Res. 2019;15(1):1-13.

19. Nazifi S, Mogheiseh A, Tabrizi AS, Rayat MH. Effect of oral melatonin administration on inflammatory cytokines and acute phase proteins after the castration of dogs. Comparative Clinical Pathology 2020:1-8.

20. Fossum TW: Surgery of the Reproductive and Genital Systems. In: Small Animal Surgery. 5th edn. Edited by Fossum TW, Duprey LP, Huff TG. Philadelphia, PA: Elsevier, Inc.; 2018: 720-732.

21. Sane A, Chokshi S, Mishra V, Barad D, Shah V, Nagpal S. Serum lipoperoxide levels in surgical stress of abdominal hysterectomy. Panminerva medica. 1993;35(3):131-3.

22. Quarterone C, Luna SPL, Crosignani N, De Oliveira FA, Lopes C, da Maia Lima AF. de Araújo Aguiar $\mathrm{AJ}$ : Ovariohysterectomy requires more post-operative analgesia than orchiectomy in dogs and cats. The Canadian Veterinary Journal. 2017;58(11):1191.

23. Gunay A, Gunes N, Gunay U. Effect of ovariohysterectomy on lipid peroxidation and levels of some antioxidants and biochemical parameters in bitches. Bull Vet Inst Pulawy. 2011;55:695-8.

24. Naziroglu M, Günay C. The levels of some antioxidant vitamins, glutathione peroxidase and lipoperoxidase during the anaesthesia of dogs. Cell Biochemistry Function: Cellular biochemistry its modulation by active agents or disease. 1999;17(3):207-12.

25. Aengwanich W, Sakundech K, Chompoosan C, Tuchpramuk P, Boonsorn T. Physiological changes, pain stress, oxidative stress, and total antioxidant capacity before, during, and after castration in male dogs. Journal of Veterinary Behavior. 2019;32:76-9.

26. Kaur G, Mishra S, Kaur A, Sehgal A, Nageswari K, Prasad R. Retention of ovaries and oxidative stress of surgery. International Journal of Gynecology Obstetrics. 2007;97(1):40-3.

27. Bureau I, Anderson RA, Arnaud J, Raysiguier Y, Favier AE, Roussel A-M. Trace mineral status in post menopausal women: impact of hormonal replacement therapy. Journal of trace elements in medicine biology. 2002;16(1):9-13. 
28. Bednarek-Tupikowska G. Antioxidant properties of estrogens. Ginekologia polska. 2002;73(1):61-7.

29. Rodriguez C, Mayo JC, Sainz RM, Antolín I, Herrera F, Martín V, Reiter RJ. Regulation of antioxidant enzymes: a significant role for melatonin. Journal of pineal research. 2004;36(1):1-9.

30. Gautier A, Graff EC, Bacek L, Fish EJ, White A, Palmer L, Kuo K. Effects of ovariohysterectomy and hyperbaric oxygen therapy on systemic inflammation and oxidation in dogs. Frontiers in Veterinary Science. 2020;6:506.

31. Yilmaz $\mathrm{O}$, Korkmaz M, Jaroszewski J, Yazici E, Ulutas E, Saritas Z. Comparison of flunixin meglumine and meloxicam influence on postoperative and oxidative stress in ovariohysterectomized bitches. Polish journal of veterinary sciences $2014,17(3)$.

\section{Figures}
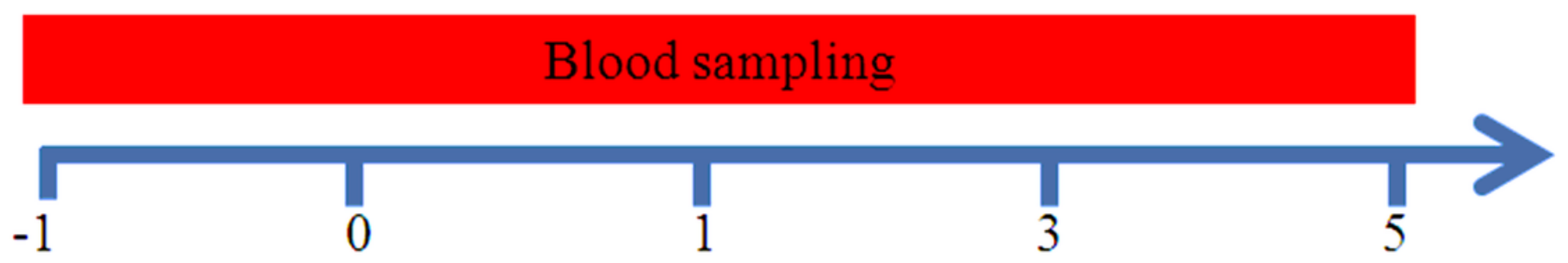

(OHE surgery)

Melatonin administration (0.3 mg/Kg/Daily, P.O)

(Melatonin, Mel+OHE+Mel, Mel+Anesthesia+Mel groups)

\section{Figure 1}

The schematic design of the study. Blood sampling and oral melatonin administration $(0.3 \mathrm{mg} / \mathrm{kg})$ were performed on days $-1,1,1,3$, and 5 of the study. Ovariohysterectomy was performed on day 0 . 

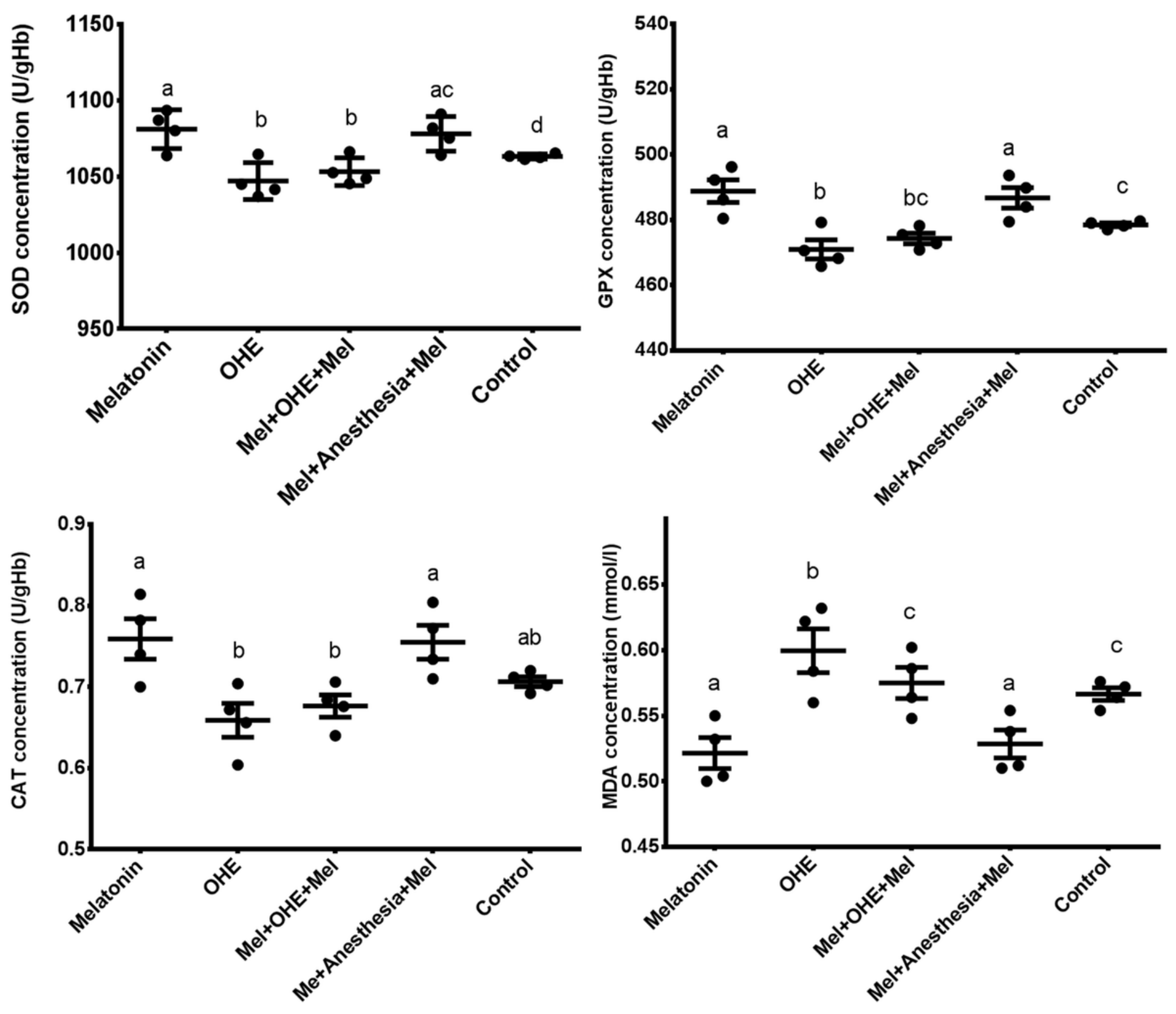

Figure 2

The mean \pm SEM levels of superoxide dismutase (SOD), glutathione peroxidase (GPX), catalase (CAT), and malondialdehyde (MDA) were compared between the study groups (melatonin, OHE, melatonin+OHE+melatonin, melatonin+anesthesia+melatonin, and control). Melatonin $(0.3 \mathrm{mg} / \mathrm{kg}) \mathrm{was}$ administrated before and after ovariohysterectomy and anesthesia. Different letters on bars indicate significant differences.

\section{Supplementary Files}

This is a list of supplementary files associated with this preprint. Click to download.

- AuthorChecklistFull.pdf 
Page 16/16 